$03 ; 10$

\title{
Сонолюминесценция суспензий нерастворимых наночастиц карбонила хрома в воде и неорганических кислотах
}

\author{
(ㄱ Г.Л. Шарипов, Б.М. Гареев, А.М. Абдрахманов \\ Институт нефтехимии и катализа РАН, Уфра, Россия \\ E-mail: glus@anrb.ru
}

Поступило в Редакцию 1 августа 2018 г.

Впервые описаны процесс приготовления и сонолюминесценция нанодисперсных суспензий $\mathrm{Cr}(\mathrm{CO})_{6}$ в воде, $83 \% \mathrm{H}_{2} \mathrm{SO}_{4}$ и $74 \% \mathrm{H}_{3} \mathrm{PO}_{4}$. В спектрах однои многопузырьковой сонолюминесценции этих суспензий зарегистрированы линии атома хрома, аналогичные соответствующим линиям в спектрах сонолюминесценции истинных растворов $\mathrm{Cr}(\mathrm{CO})_{6}$ в додекане. Сонолюминесценция нанодисперсных суспензий карбонила металла, с помощью которой была измерена электронная температура, достигаемая в пузырьках при сонолизе (от 6500 до $16000 \mathrm{~K}$ в воде и кислотах), расширяет сферу действия сонохимической модели инжекции нанокапель малолетучих соединений в кавитационные пузырьки за счет включения в нее инжекции наночастиц суспензий нерастворимых веществ.

DOI: $10.21883 /$ PJTF.2018.23.47009.17485

Непосредственное попадание растворенных веществ в кавитационные пузырьки, возникающие при сонолизе растворов, является одной из основных причин сонохимических превращений этих веществ [1]. Легче всего проникают в пузырьки растворенные газы и легколетучие соединения, например карбонилы металлов $(M e) M e(\mathrm{CO})_{n}[2,3]$. Последние, в частности, разлагаются под действием высокой температуры в пузырьках. Затем при соударениях с другими частицами в горячем газовом ядре пузырька происходит возбуждение возникших при разложении атомов металлов и испускание характерных линий, регистрируемых в 
Температура в пузырьках, измеренная при сонолизе суспензий $\mathrm{Cr}(\mathrm{CO})_{6}$ в неорганических растворителях (насыщение $-\mathrm{Ar}, T=278 \mathrm{~K}$, удельная мощность ультразвука при МПСЛ $\left.1 \mathrm{~W} \cdot \mathrm{ml}^{-1}\right)$

\begin{tabular}{c|c|c}
\hline Растворитель & Режим & $T, \mathrm{~K}$ \\
\hline $\mathrm{H}_{2} \mathrm{O}$ & сонолюминесценции & 6500 \\
& МПСЛ & 8000 \\
$\mathrm{H}_{2} \mathrm{SO}_{4}, 83 \%$ & ОПСЛ, $p_{a}=1.12 \mathrm{bar}$ & 11000 \\
& МПСЛ & 13800 \\
$\mathrm{H}_{3} \mathrm{PO}_{4}, 74 \%$ & ОПСЛ, $p_{a}=2.4 \mathrm{bar}$ & 13500 \\
& МПСЛ & 16000
\end{tabular}

спектре сонолюминесценции:

$$
\begin{gathered}
\left.\left.\left.\left[M e(\mathrm{CO})_{n}\right]_{l i q}-\right)\right)\right) \rightarrow\left[M e(\mathrm{CO})_{n}\right]_{g a s} \stackrel{t}{\rightarrow}[M e+n \mathrm{CO}]_{g a s} \\
\stackrel{t}{\rightarrow} M e^{*} \rightarrow M e+h v,
\end{gathered}
$$

где $\mathrm{Me}=\mathrm{Fe}, \mathrm{Cr}, \mathrm{Mo}, \mathrm{W} ; n=5,6$ [2].

Измеряя интенсивности атомарных линий металлов, можно определить электронную температуру, достигаемую в пузырьках [3].

Возможность участия во внутрипузырьковых сонохимических реакциях может быть ограничена растворимостью некоторых веществ в определенных жидкостях. Например, $\mathrm{Me}(\mathrm{CO})_{n}$ нерастворимы в воде и минеральных кислотах. В настоящей работе показано, что это ограничение можно преодолеть, используя нанодисперсные суспензии нерастворимых веществ.

$\mathrm{C}$ помощью сонодиспергирования кристаллов $\mathrm{Cr}(\mathrm{CO})_{6}$ в воде $(0.1 \mathrm{~g}$ в $30 \mathrm{ml})$ под действием ультразвука $(20 \mathrm{kHz}, 20 \mathrm{~W}, 10 \mathrm{~min})$ была приготовлена начальная широкофракционная суспензия. Фильтрацией через мембранный фильтр МФАС-Б-1 с размером пор $0.05 \mu \mathrm{m}$ выделена нанодисперсная фракция этой суспензии. Методом лазерного рассеяния (Shimadzu SALD-7101) установлен средний размер частиц данной фракции 15-20 nm (см. рисунок). Сохранение элементного состава наночастиц в виде $\mathrm{Cr}(\mathrm{CO})_{6}$ подтверждено их экстракцией из суспензии в додекановый раствор и совпадением спектра поглощения экстракта со

Письма в ЖТФ, 2018, том 44, вып. 23 


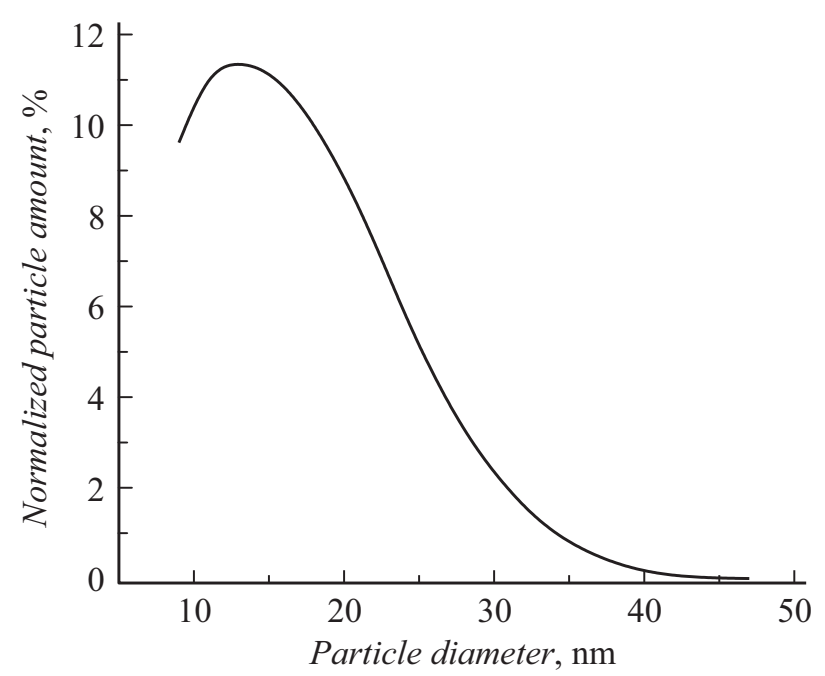

Распределение наночастиц карбонила хрома по размерам в водной суспензии.

спектром поглощения раствора в додекане исходного карбонила хрома. В дальнейшем для указанной водной суспензии были зарегистрированы линейчатые спектры атома хрома при одно- $(27.6 \mathrm{kHz}$, акустическое давление $\left.p_{a}=1.12 \mathrm{bar}\right)$ и многопузырьковой $(20 \mathrm{kHz}$, удельная мощность ультразвука $1 \mathrm{~W} \cdot \mathrm{ml}^{-1}$ )сонолюминесценции (ОПСЛ и МПСЛ соответственно). Аналогичные спектры зарегистрированы и для приготовленных на основе водной суспензии нанодисперсных суспензий $\mathrm{Cr}(\mathrm{CO})_{6}$ в $83 \% \mathrm{H}_{2} \mathrm{SO}_{4}\left(28.9 \mathrm{kHz}, 2.4 \mathrm{bar}\right.$ - ОПСЛ, $20 \mathrm{kHz}, 1 \mathrm{~W} \cdot \mathrm{ml}^{-1}$ - МПСЛ) и $74 \% \mathrm{H}_{3} \mathrm{PO}_{4}\left(28.3 \mathrm{kHz}, 2.5 \mathrm{bar}\right.$ - ОПСЛ, $20 \mathrm{kHz}, 1 \mathrm{~W} \cdot \mathrm{ml}^{-1}-$ МПСЛ). Данные спектры аналогичны соответствующим спектрам ОПСЛ и МПСЛ (спектры МПСЛ получены также ранее [3]) для растворов $\mathrm{Cr}(\mathrm{CO})_{6}$ в додекане. Очевидно, в суспензиях наночастицы карбонила металла проникают в осциллирующие в ультразвуковом поле пузырьки гораздо большего, чем эти наночастицы, размера (порядка одногодесятков микрометров [4]) через стенки пузырьков. Затем они разлагаются аналогично тому, как это происходит с молекулами $\mathrm{Cr}(\mathrm{CO})_{6}$, испарившимися со стенок пузырьков, в растворе [2,3]. Полученные спектры сонолюминесценции были использованы для оценок методом 
сравнения интенсивности двух атомарных линий [1] температуры в пузырьках в неорганических жидкостях, значения которой находятся в диапазоне от $6500 \mathrm{~K}$ (МПСЛ в воде) до $16000 \mathrm{~K}$ (ОПСЛ в 74\% $\mathrm{H}_{3} \mathrm{PO}_{4}$ ) (см. таблицу). Это наивысшие значения температуры, характерные для электронной компоненты неравновесной, как показано в последнее время [5-8], плазмы, возникающей при сонолизе в кавитационных пузырьках.

Описанное наблюдение сонолюминесценции нанодисперсных суспензий $\mathrm{Cr}(\mathrm{CO})_{6}$ расширяет сферу действия известной сонохимической модели инжекции нанокапель [9], описывающей попадание нелетучих соединений из растворов в пузырьки, за счет включения в нее механизма инжекции наночастиц суспензий нерастворимых веществ.

Авторы выражают благодарность Л.А. Бадыковой за измерение размеров наночастиц на оборудовании Центра коллективного пользования Уфимского института химии РАН.

Работа выполнена в рамках государственного задания на 2018 г. (тема 0246-2018-0045).

\section{Список литературы}

[1] Grieser F., Choi P.-K., Enomoto N., Harada H., Okitsu K., Yasui K. Sonochemistry and the acoustic bubble. Elsevier, 2015. 298 p.

[2] Suslick K.S., Flint E.B., Grinstaff M.W., Kemper K.A. // J. Phys. Chem. 1993. V. 97. P. 3098-3099.

[3] Didenko Y.T., McNamara III W.B., Suslick K.S. // Phys. Rev. Lett. 2000. V. 84. P. 777-780.

[4] Borisenok V.A. // Acoust. Phys. 2015. V. 61. P. 308-332.

[5] Ndiaye A.A., Pflieger R., Siboulet B., Molina J., Dufreche J.F., Nikitenko S.I. // J. Phys. Chem. A. 2012. V. 116. P. 4860-4867.

[6] Flannigan D.J., Suslick K.S. // J. Phys. Chem. Lett. 2012. V. 3. P. 2401-2404.

[7] Flannigan D.J., Suslick K.S. // J. Phys. Chem. B. 2013. V. 117. P. 15886-15893.

[8] Pflieger R., Ouerhani T., Belmonte T., Nikitenko S.I. // Phys. Chem. Chem. Phys. 2017. V. 19. P. 26272-26279.

[9] Xu H., Eddingsaas N.C., Suslick K.S. // J. Am. Chem. Soc. 2009. V. 131. P. 6060 6061.

Письма в ЖТФ, 2018, том 44, вып. 23 